\title{
Liquid Secondary Ion Mass Spectrometry Analysis of Permethylated, n-Hexylamine Derivatized Oligosaccharides. Application to Baculovirus Expressed Mouse Interleukin-3
}

\author{
Kenneth E. Hogeland, Jr., Brian Arbogast, and Max L. Deinzer \\ Departments of Chemistry and Agricultural Chemistry, Oregon State University, Corvallis, Oregon, USA
}

Reductive amination with $\mathrm{n}$-hexylamine followed by permethylation was used as a procedurc for the liquid secondary ion mass spectrometry (LSIMS) analysis of Asn-linked oligosaccharides. Initial experiments with this procedure were performed on maltoheptaose. These experiments show that exhaustive methylation at the newly formed secondary nitrogen forms a quaternary ammonium salt. When this is subjected to positive ion LSIMS, an abundant $\mathrm{M}^{+}$ion is observed. This procedure was applied to the Asn-linked oligosaccharides released from human transferrin and ribonuclease- $B$. The reductively aminated, permethylated mixture of oligosaccharides from ribonuclease-B afforded a positive ion LSI mass spectrum in which $\mathrm{M}^{+}$ions for $\mathrm{Man}_{5-9} \mathrm{GlcNAc}_{2}$ could be assigned. The positive ion LSI mass spectrum obtained from the mixture of oligosaccharides isolated from human transferrin showed $\mathrm{M}^{+}$ions that could be assigned to both monosialylated and disialylated biantennary complex type oligosaccharides. Reductive amination followed by permethylation of the Asn-linked oligosaccharides isolated from baculovirus expressed mouse interleukin-3 produced in Bombyx mori gave a positive ion LSI mass spectrurm in which the oligosaccharides could be assigned the munosaccharide composition Man $_{2-4}\left[\mathrm{Fuc}_{\mathrm{G}} \mathrm{GICNAc}_{2}\right.$ and $\mathrm{Man}_{2} \mathrm{GlCNAc}_{2}$. These are believed to be dimannose, trimannose, and tetramannose chitobiose core oligosaccharides, three of which are fucosylated. (J Am Soc Mass Spectrom 1992, 3, 345-352)

$\mathrm{O}$ ligosaccarides have been shown to be directly associated with the biological activity of many glycoproteins [1-4]; therefore, a thorough knowledge of glycoprotein oligosaccharide structure may be a key step in understanding their mechanisms of activity. Many analytical techniques have been developed for the analysis of oligosaccharides, and one very useful technique has been mass spectrometry $[5,6]$. Liquid secondary ion mass spectrometry (LSIMS) is the tool that has given the glycoprotein researcher the ability to accurately measure the mass of oligosaccharides and to obtain structurally significant sequence information $[7,8]$. LSIMS cumbined with other analytical techniques, such as gas chromotography/mass spectrometry, becomes a powerful tool in the structure elucidation of glycoprotein oligosaccharides.

The inherent insensitivity of oligosaccharides to LSIMS requires that they be derivatized to analyze

Address reprint requests to Max L. Deinzer, Department of Agricultural Chemistry, Oregon State University, Corvallis, OR 97331. the microscale quantities often obtained from glycoproteins. Many excellent derivatization methods have been developed for the mass spectrometric analysis of oligosaccharides [5], and two techniques, peracetylation and permethylation, have been extensively used. Problems often encountered when permethylation is employed are undermelhylation and sudium ion adduction. Undermethylation can make the assignment of the molecular ion difficult, while both undermethylation and sodium ion adduction spread the molecular ion over a range of masses decreasing its intensity.

Another class of derivative that has been developed makes use of aromatic amines that are attached to the reducing end of the oligosaccharide by reductive amination [9-13].

This procedure was first developed as a method to introduce a chromophore on the oligosaccharide to aid in UV or fluorescence detection during chromatography $[10-12,14]$. It was also found that these derivatized oligosaccharides were amenable to LSIMS analysis. The derivative that has seen the most 
frequent use has been ethyl p-aminobenzoate and good results have been obtained using this derivative. It has also been shown that by increasing the length of the $n$-alkyl chain of $n$-alkyl $p$-aminobenzoates from ethyl to tetradecyl, a significant increase in their mass spectral sensitivity is observed [9]. A problem with these derivatives is that as the ester chain length increases, the solubility of the derivative decreases and thus the yield of the derivatized oligosaccharide also decreases. Also, the higher homologs (n-hexyl, n-octyl, n-decyl, and n-tetradecyl) are not readily available and, therefore, must be prepared in house.

The advantage of derivatization with aromatic amines is the increased UV absorbance for detection during separation and desalting of the oligosaccharides by high-performance liquid chromatography (HPLC). Recent developments in high pH anion exchange chromotography (HPAEC) coupled with pulsed amperometric detection (PAD) has made available a system with which oligosaccharides can be detected with excellent sensitivity (10-100 pmol) and separated with high resolution [15-19]. The PAD system eliminates the need for a chromophore and thus attachment of the aromatic amine prior to separation is unnecessary. Desalting of the oligosaccharides can be achieved by a simple microscale gel filtration column rather than desalting by HPLC, as suggested for the p-aminobenzoate esters.

In our laboratory we need a reliable derivatization method for the LSIMS analysis of Asn-linked glycoprotein oligosaccharides. We found permethylation to be inconsistent in obtaining high quality LSIMS spectra; therefore, a study on the use of n-alkylamines, in conjunction with permethylation, as derivatives for the enhancement of the molecular ion of glycoprotein oligosaccharides was undertaken. These alkylamines are readily available and they are soluble in the alcoholic solution of this reaction. In this article we describe the initial studies on the use of $\mathbf{n}$-hexylamine for the LSIMS analysis of oligosaccharides. Preliminary experiments on maltoheptaose and the Asnlinked oligosaccharides from bovine pancreatic ribonuclease $B$ and human transferrin are presented. Also presented are preliminary data on the use of n-hexylamine with permethylation for the LSIMS analysis of Asn-linked oligosaccharides released from baculovirus expressed mouse interleukin-3 (IL-3) produced in silkworm (Bombyx mori) $[20,21]$.

\section{Results and Discussion}

\section{Maltoheptaose}

Our initial experiments on reductive amination with n-hexylamine were performed on maltoheptaose. The extent of the reaction was determined by analyzing for the disappearance of maltoheptaose by HPAEC-PAD. No maltoheptaose was observed after $\sim 18 \mathrm{~h}$ (see Experimental). When the $\mathrm{n}$-hexylamine derivatized maltoheptaose was subjected to either negative or positive ion LSIMS, abundant molecular ions were observed (data not shown). Sequence ions for both spectra were consistent with the reported fragments of other reductive amination methods $[10,13]$. Sensitivity studies were performed on the reductively aminated maltoheptaose in the positive ion mode. Serial dilutions of a stock solution of the derivatized oligosaccharide were analyzed. These experiments showed that an excellent molecular ion region spectrum can be obtained with $125 \mathrm{ng}$ (101 pmol) of sample, giving a signal-to-noise $(\mathrm{S} / \mathrm{N})$ ratio of 19/1 (Figure 1a). The molecular ion peak could still be recorded with an $S / \mathrm{N}$ ratio of $2 / 1$ when $16 \mathrm{ng}$ (13 pmol) of sample was applied to the probe. These data are comparable to those obtained with $n$-hexyl and $\mathrm{n}$ octyl $\mathrm{P}$-aminobenzoates [9]. Although we did not make a detailed comparative study of the relative merits of the n-alkyl p-aminobenzoates versus those of the n-alkylamines, in our hands we found that the ethyl $\mathrm{p}$-aminobenzoate was a more difficult derivative to use than the $n$-hexylamine. Preliminary results with the higher homologs (n-heptyl through n-decyl) of the alkylamines, all of which are commercially available, show that these compounds do not suffer the same solubility problems as the long-chain benzoate esters.

To examine the mass spectral behavior of this derivative when used in conjunction with other derivatization procedures, the n-hexylamine derivatized maltoheptaose was peracetylated or permethylated and subjected to positive ion LSIMS. Peracetylation of the n-hexylamine derivatized maltoheptaose afforded a positive ion LSIMS spectrum with an $\mathrm{MH}^{+}$ peak with $m / z 2248$ (Figure 2a). A series of sequence peaks, formed by B-type cleavage with charge retention at the nonreducing end [22], were observed with $m / z 1771,1483,1195,907,619$, and 331. Another series of peaks $60 \mathrm{u}$ below the B-type fragments are
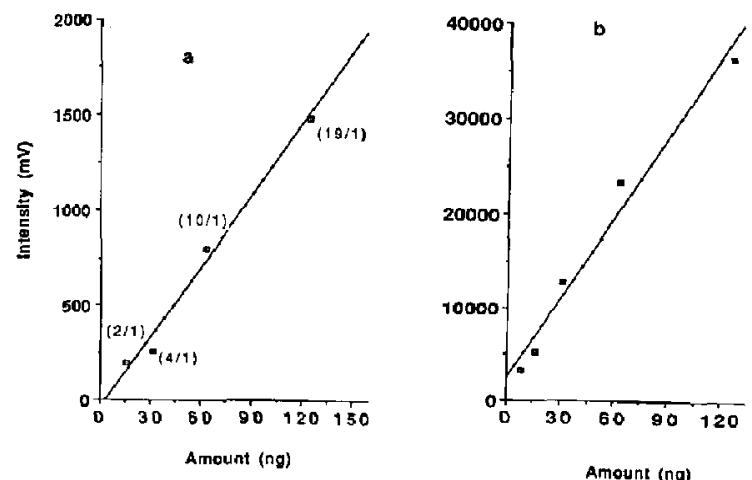

Figure 1. (a) Plot of $\mathrm{MH}^{+}$ion intensity versus amount for n-hexylamine derivatized maltoheptaose. Each data point is an average of three values. Numbers in parenthesis are $S / N$ ratio values, (b) Plot of $\mathrm{M}^{+}$ion intensity versus amount for $\mathrm{n}$ hexylamine, permethylated derivatized maltoheptaose. Each data point is an average of three values. 


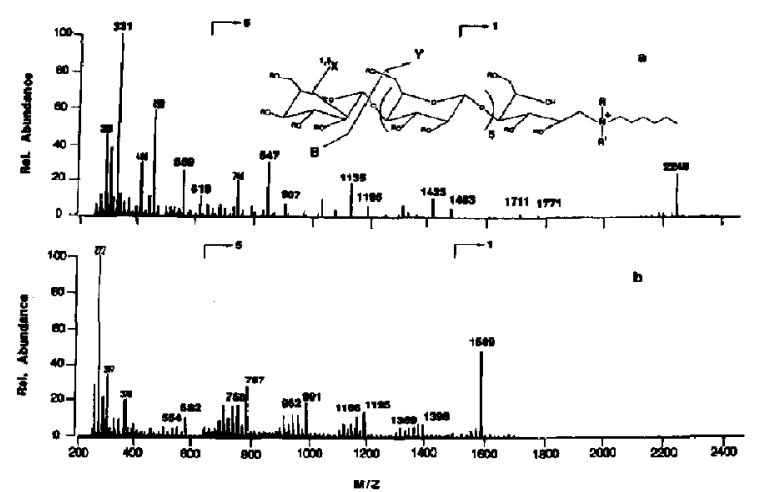

Figure 2. (a) Positive ion spectrum of reductive aminated peracetylated maltoheptaose (1.3 $\mathrm{nmol})$. Matrix: 3-nitrobenzyl alcohol. $R=A c, R^{\prime}=H$. (b) Positive ion spectrum of reductively aminated, permethylated maltoheptaose $(550$ pmol). Matrix: thioglycerol/glycerol (2:1). $\mathrm{R}=\mathrm{CH}_{3}, \mathrm{R}^{\prime}=\mathrm{CH}_{3}$.

believed to arise from the loss of neutral acetic acid by $\beta$-elimination at positions 2,3 of each glucose ring and are observed with $m / z$ 1711, 1423, 1135, 847, and 559. This loss has been observed in the low energy collision-induced dissociation (CID) mass spectrometry of peracetylated oligosaccharides [23] and is believed to be characteristic of a 1,4 linkage between monosaccharide residues.

The permethylation of the $n$-hexylamine derivatized maltoheptaose and subsequent positive ion LSIMS gave a very strong ion with $m / z 1589$ (Figure 2b). This is $\mathbf{1 5} \mathrm{u}$ higher than the calculated molecular weight and is believed to be formed by exhaustive methylation at the secondary nitrogen. This forms a quaternary ammonium salt and gives an intense $M^{+}$ molecular ion. Sequence ions, formed by Y-cleavage, are observed with $m / z 1369,1166,962,758$, and 554 . Fragmentation by ${ }^{1,5} \mathrm{X}$-cleavage leaving a formyl group at the reducing end gives another series of ions $29 \mathrm{u}$ higher than those resulting from Y-cleavage [22]. These are observed with $m / z$ 1398, 1195, 991, 787, and 582.

Both peracetylation and permethylation of the $n$ hexylamine derivatized maltoheptaose gave good spectra in positive ion LSIMS, but the permethylated compound was the more sensitive, giving an excellent spectrum with 550 pmol (compare Figure $2 a$ and b). Sensitivity studies were performed with the permethylated, n-hexylamine derivatized maltoheptaose and, as before, serial dilutions were made on a stock solution of the sample. Excellent sensitivity was achieved with $31 \mathrm{ng}$ ( $20 \mathrm{pmol}$ ) of sample and the molecular ion was easily recorded with $8 \mathrm{ng}$ ( $5 \mathrm{pmol}$ ) of sample (see Figure 1b). The excellent mass spectral sensitivity of this derivatization method is believed to be the result of the formation of the quaternary ammonium ion at the amine nitrogen by permethylation. This places an already charged species at the surfaces of the matrix due to the increased surface activity of the now hy- drophobic oligosaccharide. This increase in sensitivity due to the preformed cation and increased surface activity has been observed previously [24-26].

\section{Human Transferrin and Ribonuclease $B$}

After having obtained good sensitivity by using the $\mathrm{n}$-hexylamine-permethylation procedure, the general utility of this procedure for the analysis of glycoprotein oligosaccharides was examined. Human transferrin and bovine pancreatic ribnnuclease $B$ were chosen as models for this work.

Human transferrin is reported to contain both triantennary and biantennary Asn-linked complex-type oligosaccharides $[27,28]$. The major glycans are biantennary and differ only in their number of neuraminic acid residues, disialylated and monosialylated, with the disialylated species predominating [18, 27,28 ]. Reductive amination with $n$-hexylamine followed by permethylation was performed on the $N$ glycanase released mixture of oligosaccharides from transferrin. This was then subjected to positive ion LSIMS (Figure 3). The high mass region of the spectrum shows two $\mathrm{M}^{+}$ions that correspond to the molecular ions of monosialylated and disialylated species: $m / z 2523$ and 2885 . Also observed is cleavage at the chitobiose unit for the disialylated species with $m / z$ 2494. Peaks in the low mass region could be assigned to all the expected permethylated fragments (Figure 4) [7, 8].

The glycoprotein ribonuclease B is reported to contain Asn-linked high mannose type oligosaccharides $\mathrm{Man}_{5-9}$ GlcNAc $_{2}[29,30]$. Treatment of this glycopro-

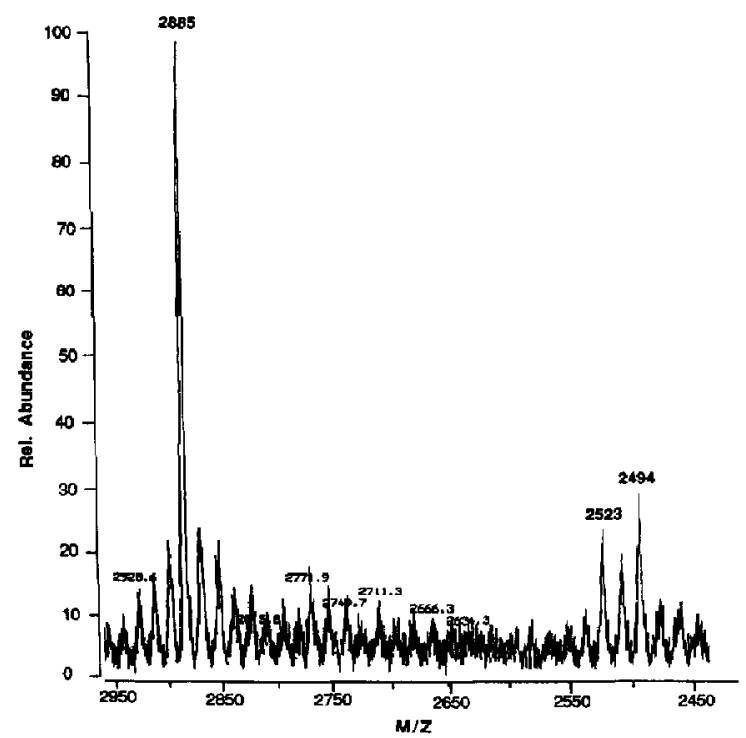

Figure 3. High mass positive ion spectrum of reductively aminated, permethylated Asn-linked oligosaccharides isolated from human transferrin. Matrix: thioglycerol/glycerol (2:1). 


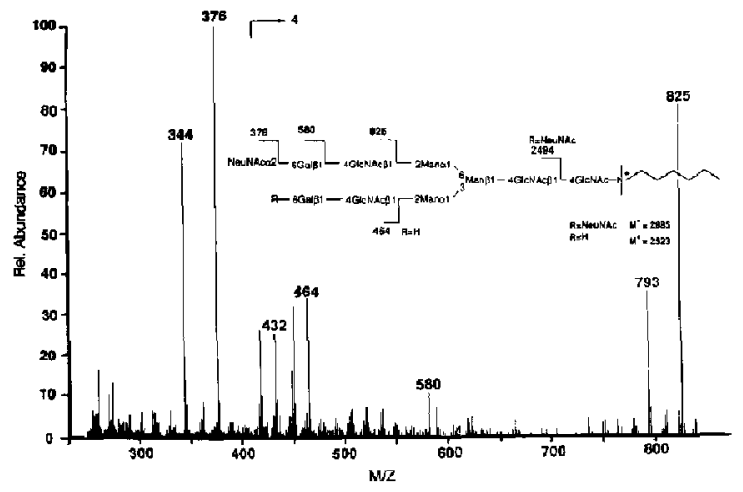

Figure 4. Low mass positive ion spectrum of reductively aminated, permethylated Asn-linked oligosaccharides isolated from human transferrin. Matrix: thioglycerol/glycerol (2:1).

tein with $\mathrm{N}$-glycanase to release the Asn-linked oligosaccharides, followed by reductive amination with $\mathrm{n}$-hexylamine, then permethylation, afforded a mixture of derivatized oligosaccharides. Positive ion LSIMS of this mixture gave a series of high mass ions with $m / z 2490,2284,2080,1875$, and 1671 . These peaks could be readily assigned to molecular ions $\mathrm{M}^{+}$for high mannose type oligosaccharides $\mathrm{Man}_{5-9} \mathrm{GlcNAc}_{2}$ (Figure 5). Few fragment ions were observed in this spectrum, but peaks that are due to B-type cleavage at the chitobiose disaccharide unit for $\mathrm{Man}_{6} \mathrm{GlcNAc}_{2}$ and $\mathrm{Man}_{5} \mathrm{GlcNAc}_{2}$ were recorded with $\mathrm{m} / \mathrm{z} 1486$ and 1280 . Another set of peaks that are 145 $\mathrm{u}$ lower than the $\mathrm{M}^{+}$ions were assigned to oligosaccharides that had not reacted with the n-hexylamine. This results in a solely permethylated species in which the reducing end $\mathrm{N}$-acetylglucosamine remains in the pyranose form and the anomeric hydroxyl group is methylated. B-type cleavage of this anomeric methoxy group forms an oxonium ion at the reducing end of the oligosaccharide. This ion is observed as a peak 145

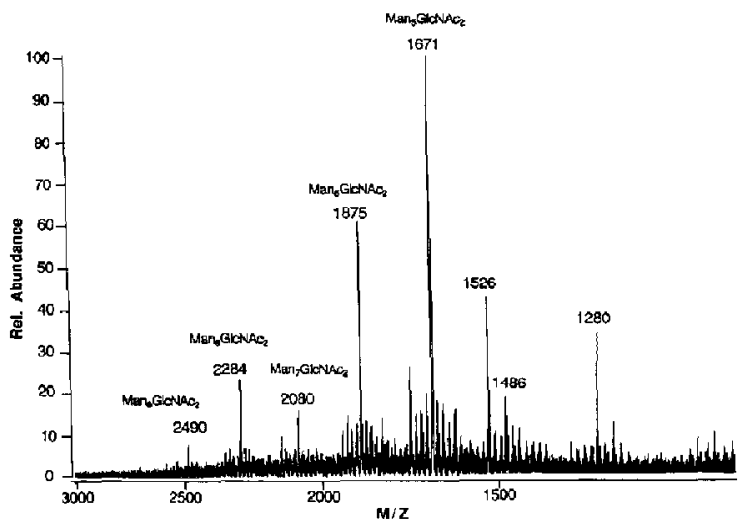

Figure 5. Positve ion spectrum of reductively aminated, permethylated Asn-linked oligosaccharides isolated from bovine ribonuclease B. Matrix: thiogylcerol/glycerol (2:1). u below the $\mathrm{M}^{+}$ion of the reductively aminated permethylated species. The predominant ion in this series has $m / z 1526$.

These ions might also be formed by fragmentation of the molecular ion $\mathrm{M}^{+}$. This possibility was investigated by performing $\mathrm{B} / \mathrm{E} \mathrm{CID}$ linked scan experiments on the $\mathrm{M}^{+}$ion with $m / z$ 1671. In these experiments no ions with $\mathrm{m} / z 1526$ were observed, indicating that the ions $145 \mathrm{u}$ below $\mathrm{M}^{+}$are the result of underderivatization. An improvement in the extent of reaction could be obtained if the reaction mixture was heated to $75^{\circ} \mathrm{C}$ for $2 \mathrm{~h}$ instead of allowing it to stand overnight. This procedure decreased the amount of underderivatization but did not eliminate it.

To determine if this derivatization procedure could be applied to oligosaccharides isolated by HPAEC-PAD, the oligosaccharides from $1.0 \mathrm{mg}(61$ nmol) of ribonuclease $B$ were released and half of this sample was used for isolation by this procedure. HPAEC-PAD of these oligosaccharides gave the chromatogram shown in Figure 6 . The peak indicated was isolated and subjected to the reductive aminationpermethylation procedure. The derivatized sample was dissolved in $10 \mu \mathrm{L}$ of acetonitrile, and $2 \mu \mathrm{L}$ were used to obtain the spectrum in Figure 6 which shows the molecular ion for $\mathrm{Man}_{6} \mathrm{GLcNAc}_{2}$ with $\mathrm{m} / z 1876$ and its fragment with $m / z 1486$. The molecular ion for $\mathrm{Man}_{5} \mathrm{GlcNAc}_{2}$ is also observed and is due to chromatographic tailing in the collection procedure.

\section{Interleukin-3}

Having established the utility of the $\mathrm{n}$-hexylamine reductive amination-permethylation procedure for

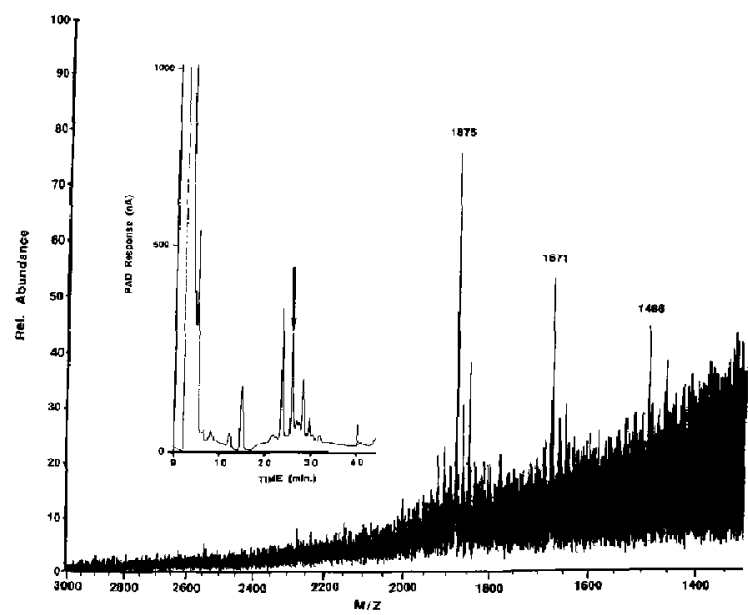

Figure 6. Postive ion spectrum of reductively aminated, permethylated Man ${ }_{6} \mathrm{GlCNAc}_{2}$ isolated by HPAEC-PAD prior to derivatization. Inset shows chromatogram of the oligosaccharides released from ribontuclease $B$. The arrow identifies the peak collected for derivatization and mass spectral analysis. Matrix: thioglycerol/glycerol (2:1) 
LSIMS analysis of oligosaccharides, the analysis of the Asn-linked oligosaccharides of baculovirus expressed mouse IL-3 was undertaken. Recently we subjected this sample to electrospray mass spectral analysis. This experiment revealed the presence of four glycoproteins with masses of 16,545, 17,278, 17,422 , and $17,584 \mathrm{u}$. The calculated average molecular weight of a single IL-3 glycoprotein whose structure without carbohydrate was predicted from the nucleotide sequence is $15,674 \mathrm{u}$ or $15,670 \mathrm{u}$ if the disulfide linkages are taken into account [31]. The estimated combined molecular weights of the carbohydrates, accordingly, would be $875,1608,1752$, and $1844 \mathrm{u}$.

Our initial reports on the monosaccharide analysis by HPAEC-PAD [21] of the hydrolyzed glycoprotein shows the monosaccharide composition to be fucose, mannose, and $\mathrm{N}$-acetylglucosamine. The presence of fucose is also substantiated by LSIMS of the acetolysis mixture of oligosaccharides from IL-3 [21]. Peracetylated ions that could be assigned to fucose and fucosylated species were observed with $\mathrm{m} / \mathrm{z} 273$ and 1136 [21, 32].

Treatment of $240 \mu \mathrm{g}(13.8 \mathrm{nmol})$ of IL-3 with $\mathrm{N}$ glycanase followed by reductive amination and permethylation afforded the positive ion LSIMS spectrum (Figure 7). Three ions with $m / z$ 1059, 1233, and 1438 are believed to be molecular ions with the monosaccharide compositions of $\mathrm{Man}_{2} \mathrm{GlcNAc}_{2}$ $\mathrm{N}^{+} \mathrm{Me}_{2} \mathrm{Hexyl}, \quad \mathrm{Man}{ }_{2}$ [Fuc]GlcNAc ${ }_{2}-\mathrm{N}^{+} \mathrm{Me}_{2} \mathrm{Hexyl}$, and $\mathrm{Man}_{3}$ [Fuc]GlcNAC ${ }_{2}-\mathrm{N}^{+} \mathrm{Me}_{2}$ Hexyl. Fragment ions at $m / z 668$ and 872 are the result of B-typc cleavage at the chitobiose disaccharide unit (Figure 7). The loss of methanol from both of these ions to give peaks with $m / z 636$ and 840 indicates that the bond between Man-GlcNAc is a 1,4 linkage. Two ions at $m / z 1088$ and 914 are the result of incomplete derivatization by n-hexylamine and can be assigned to the oxonium ions $\operatorname{Man}_{2}\left[\right.$ Fuc] GlcNAc 2 and $\mathrm{Man}_{2} \mathrm{GlCNAc}_{2}^{+}$. A much less intense ion with $\mathrm{m} / z 1641$ is believed to

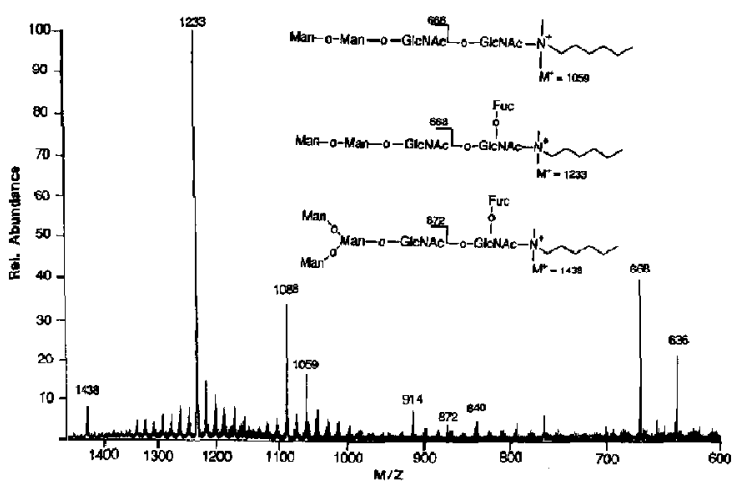

Figure 7. Positive ion spectrum of reductively aminated, permethylated Asn-linked oligosaccharides isolated from $240 \mu \mathrm{g}$ $(13.8 \mathrm{nmol}$ ) of baculovirus expressed IL-3 produced in silkworm. Matrix: thioglycerol/glycerol (2:1). be the $\mathrm{M}^{+}$ion for $\mathrm{Man}_{4}\left[\mathrm{Fuc}_{G} \mathrm{GlcNAc}_{2}-\mathrm{N}^{+} \mathrm{Me}_{2} \mathrm{Hexyl}\right.$ (data not shown).

These data obtained for the silkworm-produced IL-3 show that the Asn-linked oligosaccharides are severely truncated and extensively fucosylated. Although no direct data have been obtained on the isolated individual oligosaccharides, their structures are believed to be dimannose, trimannose, tetramannose chitobiose core oligosaccharides, three of which are fucosylated. The fucose residue is thought to be bound to the reducing end $\mathrm{N}$-acetylglucosamine. This is apparent from the fragmentation at the chitobiose core unit (Figure 7 ).

\section{Conclusion}

The data presented in this article show that $n$ alkylamines may be used to form derivatives with oligosaccharides for their analysis by LSIMS. Our initial studies with n-hexylamine and maltoheptaose show that this derivative affords mass spectral sensitivities comparable to those obtained by using the p-aminobenzoate ester derivatives. Permethylation of the reductively aminated oligosaccharides consistently gave intense molecular ions $\mathrm{M}^{+}$with little undermethylation. Our experiments with the model glycoproteins show that this procedure can be directly applied to the analysis of mixtures of Asn-linked oligosaccharides or the oligosaccharides isolated by HPAEC-PAD. This method was developed to provide a reliable procedure for the analysis of low microgram quantities of oligosaccharides by LSIMS. In our hands permethylation alone did not consistantly give the same quality spectra obtained by this alternate procedure. We feel this procedure is an excellent alternative for obtaining high quality LSIMS spectra of glycoprotein oligosaccharides. Our studies on the characterization of oligosaccharides from baculovirus expressed mouse IL-3 are continuing.

\section{Experimental}

Maltoheptause, buvine pancreatic ribonuclease $\mathrm{B}$, human transferrin, sodium cyanoborohydride, nonidet P-40 (NP-40), sodium lauryl sulfate, Sephadex G-10 gel $(40-120 \mu)$, and $\beta$-mercaptoethanol were purchased from Sigma Chemical (St. Louis, MO). Bio-Gel P-2 $(130 \mu)$ was purchased from Bio Rad (Richmond, CA). DMSO, silylation grade, and Reacti vials were purchased from Pierce (Rockford, IL). n-Hexylamine was from Matheson Coleman and Bell (East Rutherford, NJ). Iodomethane $>99 \%$ was purchased from Fluka (Ronkonkoma, NY). Sodium hydroxide was reagent grade. Glacial acetic acid was Baker analyzed HPLC grade. All solvents were HPLC grade and water was purified by passage through a Milli-Q purifcation system. Sodium acetate was reagent grade from EM Science (Gibbstown, NJ). N-glycanase 
(E.C.3.5.1.52.) was purchased from Genzyme (Cambridge, MA). Baculovirus expressed interleukin- 3 was a gift from DNAX Research Institute of Molecular and Cellular Biology, Palo Alto, CA. All reactions were performed in $1 \mathrm{~mL}$ or $3 \mathrm{~mL}$ Reacti vials that had been treated with dichlorodimethylsilane. All masses were rounded to integral values.

\section{Release of Asn-linked Oligosaccharides from Glycoproteins}

Oligosaccharides were released as previously described. ${ }^{1}$ Glycoproteins were dissolved in $0.5 \%$ SDS/0.1 M $\beta$-mercaptoethanol solution to give a protein concentration of $2.0 \mathrm{mg} / \mathrm{mL}$. These were heated in boiling water for $3.0 \mathrm{~min}$ then diluted to a protein concentration of $1.0 \mathrm{mg} / \mathrm{mL}$ with $0.55 \mathrm{M}$ sodium phosphate buffer at $\mathrm{pH} 8.6$. To this was added 7.5\% $(\mathrm{w} / \mathrm{w}) \mathrm{NP}-40$ to give a final concentration of 0.9 $\mathrm{mg} / \mathrm{mL}$. N-glycanase was added to give 0.1 unit of enzyme per $20 \mu \mathrm{g}$ of glycoprotein.

After mixing, the solution was incubated overnight $(18-22 \mathrm{~h})$ at $37^{\circ} \mathrm{C}$. Protein was removed by ethanol precipitation by addition of three volumes of cold ethanol. Samples were centrifuged and the supernatants were concentrated under a stream of nitrogen until a thick syrup remained $(50-100 \mu \mathrm{L})$. These were diluted with enough water for desalting. Oligosaccharides from transferrin and ribonuclease $B$ were desalted on P-2 and G-10 gels, respectively, by spin gel filtration. IL-3 was not desalted at this point. The amount of each glycoprotein used was $2.1 \mathrm{mg}$ of transferrin, $1.9 \mathrm{mg}$ and $1.0 \mathrm{mg}$ of ribonuclease $\mathrm{B}$, and $240 \mu \mathrm{g}$ of IL-3.

\section{Derivatization of Maltoheptaose with n-Hexylamine [14]}

Maltoheptaose $(1.1 \mathrm{mg}, 0.95 \mu \mathrm{mol}-4.1 \mathrm{mg}, 36 \mu \mathrm{mol})$ was dissolved in 1:1 water/ethanol solution $(70 \mu \mathbf{L}$ to $400 \mu \mathrm{L}$ ). To this was added freshly distilled nhexylamine ( $100 \mu \mathrm{L}$ to $400 \mu \mathrm{L}$ ). Glacial acetic acid (20 $\mu \mathrm{L}$ to $50 \mu \mathrm{L}$ ) was then added and the solution was allowed to stand at room temperature for $3.5 \mathrm{~h}$. To this solution was added an aqueous $1.5 \mathrm{M}$ sodium cyanoborohydride solution $(0.5 \mathrm{~mL})$. This was allowed to stand at room temperature overnight $(18 \mathrm{~h})$. Alternatively, the sodium cyanoborohydride solution was added after the n-hexylamine and adjusted to $\mathrm{pH}$ 5 with glacial acetic acid. This was then heated to $75{ }^{\circ} \mathrm{C}$ for $2 \mathrm{~h}$. The solution was then extracted with $2 \times 300 \mu \mathrm{L}$ of chloroform. The aqueous layer was then concentrated under a stream of nitrogen $(\sim 50$ $\mu \mathrm{L}$ to $-300 \mu \mathrm{L})$. The concentrate $(-50 \mu \mathrm{L})$ was diluted with water to $100 \mu \mathrm{L}$ and desalted on a Sephadex G-10 gel column by spin gel filtration. The

\footnotetext{
${ }^{1}$ Genzyme Data Sheet and refs 33 and 34.
}

larger volume $(\sim 300 \mu \mathrm{L})$ was diluted to $1 \mathrm{~mL}$ and desalted on a Sephadex G-10 column packed in a $10-\mathrm{mL}$ micromate glass syringe.

\section{n-Hexylamine Derivatization of Oligosaccharides from Human Transferrin and Bovine Ribonuclease B}

Conditions were the same as for maltoheptaose, except that $50 \mu \mathrm{L}$ of $\mathrm{n}$-hexylamine was used. Oligosaccharides from transferrin were allowed to stand at room temperature and desalted by using P-2 gel. Those from ribonuclease $B$ were either allowed to stand at room temperature or heated to $75^{\circ} \mathrm{C}$. These were desalted by using G-10 gel. Samples were concentrated to dryness with nitrogen and placed into a vacuum dessicator over $\mathrm{P}_{2} \mathrm{O}_{5}$ overnight at room temperature to dry.

\section{n-Hexylamine Derivatization of Oligosaccharides Released from Baculovirus Expressed Interleukin-3}

Conditions were the same as for maltoheptaose, except $5 \mu \mathrm{L}$ of acetic acid, $15 \mu \mathrm{L}$ n-hexylamine, and 30 $\mu \mathrm{L}$ sodium cyanoborohydride solution were used. This was allowed to stand at room temperature. The sample was desalted by using G-10 gel and concentrated to dryness with nitrogen, then placed into a vacuum dessicator over $\mathrm{P}_{2} \mathrm{O}_{5}$ at room temperature overnight.

Spin Gel Filtration [35, 36]. G-10 and P-2 gels were washed with $0.1 \mathrm{M}$ sodium acetate adjusted to $\mathrm{pH} 5.5$ with pyridine. Gels were loaded into $1 \mathrm{~mL}$ repeatable pipet tips as a slurry. The tips were then placed into $10 \times 75 \mathrm{~mm}$ test-tubes and centrifuged at $1400 \times \mathrm{g}$ for $6 \mathrm{~min}$ to remove the acetate solution. Samples were loaded onto the gels in no more than $50 \mu \mathrm{L}$ portions and centrifuged as above.

\section{Peracetylation of $n-H e x y l a m i n e$ Derizatized Maltoheptaose [37]}

n-Hexylamine derivatized maltoheptaose was dried overnight in a vacuum dessicator over $\mathrm{P}_{2} \mathrm{O}_{5}$ at room temperature. To the sample $(480 \mu \mathrm{g})$ was added 100 $\mu \mathrm{L}$ of acetic anhydride and $0.5 \mathrm{mg}$ sodium acetate. The vial was flushed with nitrogen, capped, and incubated at $95{ }^{\circ} \mathrm{C}$ overnight. Reagents were removed by evaporation with nitrogen. The residue was taken up in $200 \mu \mathrm{L}$ of water and extracted with $4 \times 200 \mu \mathrm{L}$ of diethyl ether. Ether was evaporated under a stream of nitrogen.

\section{Permethylation of $n$-Hexylamine Derivatized Oligosaccharides [38]}

Oligosaccharides were dried as in the case of peracetylation. Samples were dissolved in $100-200 \mu \mathrm{L}$ of dry DMSO and stirred for $10 \mathrm{~min}$ at room tempera- 
ture. Approximately $2-3 \mathrm{mg}$ of finely ground sodium hydroxide was then added, and this suspension was stirred for $6 \mathrm{~min}$ at room temperature. Iodomethane $(50 \mu \mathrm{L})$ was then added and the solution was stirred for $6 \mathrm{~min}$. An additional $50 \mu \mathrm{L}$ of iodomethane was added and stirred for $10 \mathrm{~min}$. The reaction was quenched with $200 \mu \mathrm{L}$ of water, extracted with $3 \times 200$ $\mu \mathrm{L}$ of chloroform, and the organic layer was washed with $3 \times 200 \mu \mathrm{L}$ of water. Chloroform was evaporated under a stream of nitrogen. $n$-Hexylamine derivatized maltoheptaose $(390 \mu \mathrm{g})$ were used. Oligosaccharides released from glycoproteins as described above were used.

\section{Liquid Secondary Ion Mass Spectrometry}

Mass spectrometry was carried out on a Kratos MS-50 double focusing mass spectrometer (Kratos Analytical, Ramsey, NJ) operating at a resolution of 1200-2500. A cesium ion gun operating at $12 \mathrm{keV}$ or a fast atom bombardment (FAB) gun operating at 7-8 $\mathrm{keV}$ was used to generate the primary ion beam. Ions were accelerated from the ion source at $5.3 \mathrm{keV}\left(\mathrm{Cs}^{+}\right)$ or $8 \mathrm{keV}$ (FAB). Scans were taken at $30 \mathrm{~s}$ per decade over high mass ranges in raw data and $10 \mathrm{~s}$ per decade over low mass ranges with centroided data collection. Csl in tetraethyleneglycol was used as a calibration standard. B/E CID linked scan experiments were performed by using a DS- 90 data system and a FAB source. Helium was used as a collision gas to give $50 \%$ attenuation of the parent ion. Oligosaccharides were either dissolved in water or acetonitrile for LSIMS analysis. The matrix was $1 \mu \mathrm{L}$ of either 3-nitrobenzyl alcohol or thioglycerol/glycerol (2:1).

\section{High pH Anion Exchange Chromatography [18]}

HPAEC was carried out on a Dionex BioLC system by using a pellicular anion exchange column (PA-1). The oligosaccharides were detected with a pulsed amperometric detector with detection potentials set at +0.05 , +0.65 , and $-0.94 \mathrm{~V}$ and pulse durations of 300,60 , and $180 \mathrm{~ms}$, respectively. Semipreparative experiments were made by passing the column effluent through an anion micromembrane suppressor (Dionex AMMS) for desalting on line. The AMMS regenerant solution was $35 \mathrm{mM} \mathrm{H} \mathrm{SO}_{4}$ at a flow rate of 8 $\mathrm{mL} / \mathrm{min}$. Oligosaccharides released from ribonuclease $B$ were eluted with the following program: Eluant A was $100 \mathrm{mM} \mathrm{NaOH}$, eluant $B$ was $500 \mathrm{mM}$ sodium acetate, and the flow rate was $1 \mathrm{~mL} / \mathrm{min}$. The column was preequilibrated with $100 \% \mathrm{~A}$ then, after a $5 \mathrm{~min}$ hold period, the oligosaccharides were eluted with a linear gradient from $0 \%$ to $20 \% \mathrm{~B}$ in $40 \mathrm{~min}$.

\section{Acknowledgments}

Acknowledgment is made to the National Institutes of Health (NIH grant ES00210). We thank Dr. Jolanda Schreurs for the gift of the purified IL-3. We also thank Dr. Marvin Vestal of Vestec Corp, for the electrospray mass spectral analysis of our sample. This is Oregon Agricultural Experimental Station Publication No. 9596.

\section{References}

1. Hansen, L.; Blue, K.; Barone, D.; Collen, D.; Larsen, G. R. J. Biol. Chem. 1988, 263, 15713.

2. Galili, U.; Clark, M. R.; Shohet, S. B.; Buchler, J.; Macher, B. A. Proc. Natl. Acad. Sci., U.S.A. 1987, 84, 1369.

3. Fukuda, M; Biochim. Biophy. Acta 1985, 780, 119.

4. Rademacher, T. W.; Parekh, R. B.; Dwek, R. A. Ann Rev. Biochem, 1988, 57, 785.

5. Biermann, C. J.; McGinnis, G. D., Eds.; Analysis of Carbohydrates by GLC. and MS.; CRC: Boca Raton, FL, 1989.

6. McCloskey, J. A., Ed.; Methods in Enzymology, 193, Mass Spectrometry; Acadenic: New York, 1990; Sec 3; p 539.

7. Dell, A. Ado. Carbohydr. Chem. Biochem. 1987, 45, 19.

8. Egge, H.; Peter-Katalinic, J. Mass Spectrom. Reo. 1987, 6, 331 .

9. Poulter, L.; Karrer, R.; Burlingame, A. L. Anal. Biochem. 1991, 195, 1 .

10. Wang, W. T.; LeDonne, J. C., N. C.; Ackerman, B.; Sweeley, C. C. Anal. Biochem. 1984, 141, 366.

11. Her, G. R.; Santikarn, S.; Reinhold, V. N.; Williams, J. C. J. Carbohydr. Chem. 1987, 6, 129.

12. Gillece-Castro, B. L.; Fisher, S. J.; Tarentino, A. L.; Peterson, D. L.; Burlingame, A. L. Arch. Biochem. Biophys. 1987, 256, 194.

13. Webb, J; Jiang, K.; Gillece-Castro, B. L.; Tarentino, A. L.; Plummer, T. H.; Byrd, J. C.; Fisher, S. J.; Burlingame, A. L. Anal. Biochem. 1988, 169, 337.

14. Hase, S.; Hara, S.; Matsushima, Y. J. Biochern. 1979, 85 , 217.

15. Hardy, M. R.; Townsend, R. R. Proc. Natl. Acad. Sci. 1988, $85,3289$.

16. Townsend, R. R.; Hardy, M. R.; Hindsgaul, O,; Lee Y. C. Anal. Biochem. 1988, 174, 459.

17. Hardy, M. R.; Townsend, R. R. Carbohydr. Res. 1989, 188, 1.

18. Basa, L. J.; Spellman, M. W. J. Chromatogr. 1990, 499, 205.

19. Barr, J. R.; Anumula, K. R.; Vettese, M. B.; Taylor, P. B.; Carr, S. A. Anal. Biochem. 1991, 192, 181.

20. Miyajima, A.; Schreurs, J.; Otsu, K.; Kondo, A.; Arai, K-I.; Maeda, S. Gene 1987, 58, 273.

21. Svoboda, M.; Przybylski, M.; Schreurs, J.; Miyajima, A.; Hogeland, K.; Deinzer, M. J. Chromatogr. 1991, 562, 403.

22. Domon, B.; Costello, C. E. Glycoconiugate J. 1988, 5, 397.

23. Domon, B,; Muller, D. R.; Richter, W. J. Org. Mass Spectrom. $1989,24,357$

24. Dell, A.; Carman, N. H,; Tiller, P. R,; Thomas-Oates, J. E. Biomed. Environ. Mass Spectrom. 1988, 16, 19.

25. Baldwin, M. A.; Stahl, N.; Reinders, L. G.; Gibson, B. W.; Prusiner, S. B.; Burlingame A. L. Anal. Biochem. 1990, 191, 174.

26. Ligon, V. W. Jr.; Dorn, S. B. Int. J. Mass Spectrom. Ion Proc. $1987,78,99$.

27. Spik, G.; Bayard, B.; Fournet, B.; Strecker, G.; Bouquelet, S.; Montrevil, J. FEBS. Lett. 1975, 50, 296.

28. Spik, G.; Coddeville, B.; Montreuil, J. Biochimie 1988, 70, 1459.

29. Liang, C.-J.; Yamashita, K.; Kobata, A. J. Biochem. 1980, 88 , 51. 
30. Hirani, S.; Bernasconi, R. J.; Rasmussen, R. J. Anal, Biochem. $1987,162,485$.

31. Yokota, T.; Lee, F.; Rennick, D.; Hall, C.; Arai, N.; Mosmann, T.; Nabel, G.; Cantor, H.; Araj, K. Proc. Natl. Acad. Sci. USA 1984, 81, 1070.

32. Naik, S.; Oates, E. J.; Dell, A.; Taylor, G. W.; Dey, P. M.; Pridham, J. B. Biochem. Biophys. Res. Comm. 1985, 132, 1

33. Chu, F. K. J. Biol. Chem. 1986, 261, 172.

34. Tareatino, A. C.; Gomes, C. M.; Plunumer, T. H. Jr. Biachem. $1985,24,4665$.
35. Maniatis, T.; Fritsch E. F.; Sambrook, J. Molecular Cloning: $A$ Laboratory Manual; Cold Spring Harbor Laboratory: Cold Spring Harbor, NY, 1982; p 466.

36. Dr. Tse Fang Chen, Oregon State University, Department of Agricultural Chemistry, Personal Communication.

37. Fox, A.; Morgen, L. S.; Gilbart, J. In Analysis of Carbonhydrates by GLC. and MS.; Biermann, C. J.; McGinnis, G. D., Eds.; CRC: Boca Raton, FL, 1989; p 87.

38. Ciucanu, I.; Kerk, F. Curbohydr. Res. 1984, 131, 209. 